\title{
Epidemiology of mortality among road accident victims in the south of Kerman Province, Iran, from 2012 to 2015
}

\author{
Nasiri N, MSc Student ${ }^{1}$, Vazirinejad R, $\mathrm{PhD}^{2 *}$, Rezaeian $\mathrm{M}, \mathrm{PhD}^{3}$, Sharifi $\mathrm{H}, \mathrm{PhD}^{4}$, Sanji \\ Rafsanjani M, MD ${ }^{5}$ \\ 1- MSc Student of Epidemiology, Rafsanjan University of Medical Sciences, Rafsanjan, Iran. 2- Professor, Dept. of Social \\ Medicine, Social Determinants of Health Research Center, Rafsanjan University of Medical Sciences, Rafsanjan, Iran. \\ 3- Professor, Dept. of Epidemiology and Biostatistics, Occupational Environmental Research Center, Medical School, \\ Rafsanjan University of Medical Sciences, Rafsanjan, Iran. 4- Associate Prof., of Epidemiology, HIV/STI Surveillance \\ Research Center, and WHO Collaborating Center for HIV Surveillance, Institute for Futures Studies in Health, Kerman \\ University of Medical Sciences, Kerman, Iran. 5- Assistant Prof., Dept. of Emergency Medicine, Rafsanjan University of \\ Medical Sciences, Rafsanjan, Iran.
}

\begin{abstract}
Received: May 2017, Accepted: June 2017

Background: Road accidents and their resulting deaths are important issues in the Iranian society. Identifying the distribution of mortality as a result of road accidents has a significant role in preventing this problem. The aim of this study was to investigate the frequency of road deaths in Southern Kerman Province, Iran, from 2012 to 2015.

Materials and Methods: In this cross-sectional study, the injured individuals who died due to road accidents were entered into the study by census sampling method. After entering the data into the statistical software, the frequency of the studied variables was presented in the form of text and table.

Results: In this study, the frequency of deaths was higher among motor vehicle drivers $(44.73 \%)$, and in cases with head injury (40.68\%) and automobiles (68.85\%), and in accidents in the spring and autumn (respectively, 28.28\% and 25.66\%) compared to other groups.

Conclusions: Since victims with head injuries and drivers of vehicles had the highest frequency of death in this study, it seems that increasing the use of protective equipment (belts and helmet) has a significant role in reducing the rate of mortality due to driving accidents in this area.
\end{abstract}

Keywords: Death, Epidemiology, Accidents, Iran.

\section{Introduction}

Road accident is a public health problem. Approximately 1.2 million people die each year on roads in the world $(1,2)$. It is estimated that road accident injury is the ninth cause of death worldwide (1), and is expected to be the seventh cause of death in $2030(1,2)$. Between 20 and 50 million people suffer from non-fatal injuries due to road accidents in the world $(1,2)$. Moreover, $90 \%$ of deaths from road accidents occur in countries with low and middle income, while these countries account for $54 \%$ of the vehicles worldwide $(1,2)$.

The first death from road accidents in Iran dates back to December 1926 (3). According to the World Health Organization (WHO), the death rate from road accidents in Iran is 32.1 per 100,000 people $(1,4)$. The rate of death due to road accidents in Iran is higher than all the countries of the Eastern Mediterranean region (5) and is almost twice the global average (1). The third cause of death in Iran is death due to road accidents (6). Although the rate of deaths due to road accidents in developed countries has fallen in the last four decades, it has risen in Iran (3).

Road accidents in Iran lead to fatal and nonfatal injuries (7). Given the high incidence of death and injuries due to road accidents, the

\footnotetext{
* Corresponding author: Reza Vazirinejad, Dept. of Social Medicine, Social Determinants of Health Research Center, Rafsanjan University of Medical Sciences, Rafsanjan, Iran.

E-mail: rvazirinejad@yahoo.co.uk
} 
prevention of these accidents is a necessity (8). Emergency medical services (EMS) are emergency medical care provided to the patient before arriving at the hospital. EMS is provided by a group with a variety of abilities and skills from the scene of the accident to bedside (9). EMS, in addition to the transference of injured patients to the hospital, should provide the necessary care for the stabilization of vital signs, and prevention of injury, death, and disability (10). EMS plays a vital role in increasing survival and reducing disability in a large number of patients (9). When the onset of treatment of life-threatening events is at the scene of an accident, the mortality rate is reduced compared when the onset of treatment is in the hospital $(11,12)$.

Poor or delayed emergency care can exacerbate post-accident injuries (13) and improved emergency services help reduce the prevalence of death and disability $(14,15)$. In countries with low and moderate income, most of the deaths due to trauma occur in the prehospital emergency phase. The speed of arrival of the emergency medical team at the scene of the accident and the suitable transfer of victims by trained individuals may reduce the severity of damage and preventable deaths (16). Despite the grave importance of EMS in the prevention of mortality and morbidity due to road accidents, there is little information in this regard (17).

In a study conducted in Fars Province, Iran, $77.8 \%$ of the dead were men and $22.19 \%$ were women. The highest mortality rate was in the age group of 25-34 years. Moreover, $43.65 \%$, $35.75 \%$, and $18.93 \%$ of the deceased were drivers, occupants, and pedestrians, respectively. Among the deceased due to road accidents, head injury (71.5\%) was the most prevalent cause of death (18).

Kerman Province is the second most populous province in Iran with a population of about 3 million people in 23 cities, 7 of which are in the south of the province (19). According to the report of the Department of Forensic Medicine of the country, there has been a reduction in road traffic deaths in Kerman
Province, in 2016 relative to 2015 (20). Since quantitative studies have been conducted in the south of the province on the distribution of death due to road accidents, the aim of this study was to identify the number and distribution of deaths from road accidents among cases transferred to Emam Khomeini Hospital in Jiroft City, Iran, by the emergency department.

\section{Material and Methods}

This was a cross-sectional study. The study population consisted of all traffic accident victims who were transferred to Imam Khomeini Hospital of Jiroft City by the 115 Emergency responders of the south of Kerman Province and died at the scene of the accident or in the hospital until 30 days after the accident from 2012 to 2015.

In this study, the data collection tool was a checklist designed by the researcher using the 115 Emergency responders' mission information form. Variables such as age, gender, traffic passages, the role of the injured, accident time, vehicle, season, year, and types of trauma were considered as independent variables and death was considered as the dependent variable. In this study, in addition to examining all 115 Emergency mission forms in the 115 Emergency archive of the south of Kerman Province, the mission forms of the injured were separately and accurately checked, the information of the mission forms of the deceased at the scene of the accident were recorded, and the forms of the injured who were taken to the hospital from the accident scene by the 115 Emergency were entered into the checklist.

After collecting the data on medical emergencies, the researchers first referred to the statistics unit of the hospital to investigate the outcome of the 115 Emergency missions and deaths due to driving accidents up to 30 days after the accident, and received the data on the deceased due various reasons from the statistics unit of Imam Khomeini Hospital of Jiroft City during the years 2012 to 2015. 
After removing the registration number of the file of the deceased due to driving accidents, the researchers referred to the hospital archives and, in addition to collecting and verifying the records of all deaths due to driving accidents, entered the information of the deceased and injured individuals, who were transferred to the hospital by the 115 Emergency responders, into the checklist.

The data of all injured individuals who had died before the 115 Emergency responders had arrived at the scene of the accident, and those who had been transferred from the scene of the accident to the hospital by the 115 Emergency responders and died in the hospital up to 30 days after the accident were included in the study. The injured individuals who had been taken to the hospital from other health centers by the 115 Emergency responders or transported from the accident site by passing vehicles and picked up by the 115 Emergency responders on the way were excluded from the study.

The 115 Emergency responders' emergency form was used to aggregate data from the 115
Emergency Unit and hospital. The data of the two centers were linked by first and family name, date, code of the 115 Emergency Unit base, and mission form number. After completing the checklist, all the data were entered into Excel software, and then, analyzed using Stata software (version 12, StataCorp, College Station, TX). First, the frequency of deaths at the scene of the accident and the hospital were calculated separately, and then, the overall frequency of the deaths was calculated.

\section{Results}

In this study, which was conducted based on the data from 115 Emergency Unit of Southern Kerman Province and Imam Khomeini Hospital of Jiroft City, $76.88 \%$ of the deaths were among men. Deaths in the age group of 19-30 years at the scene of the accident and in the hospital were more than other age groups. In total, $42.23 \%$ of the deaths due to road accidents were in the age group of 19-30 years (Table 1).

Table 1: Frequency of death due to road accidents in age and sex groups from 2012 to 2015

\begin{tabular}{ccccc}
\hline \multirow{2}{*}{ Variable } & \multicolumn{2}{c}{ Percentage, frequency, and number of deaths of individuals injured } \\
\cline { 2 - 5 } & & Scene of the accident & Hospital & Generally \\
\hline & $\leq \mathbf{1 8}$ & $31(17.22)$ & $12(10.34)$ & $43(14.53)$ \\
\cline { 2 - 5 } Age group & $\mathbf{1 9 - 3 0}$ & $71(39.44)$ & $54(46.55)$ & $125(42.23)$ \\
\cline { 2 - 5 } & $\mathbf{3 1 - 4 4}$ & $34(18.89)$ & $21(18.10)$ & $55(18.58)$ \\
\cline { 2 - 5 } & $\mathbf{4 5 - 6 4}$ & $32(17.78)$ & $17(14.66)$ & $49(16.55)$ \\
\cline { 2 - 5 } & $\mathbf{6 5} \leq$ & $12(6.67)$ & $12(10.34)$ & $24(8.11)$ \\
\hline \multirow{2}{*}{ Gender } & Male & $160(75.12)$ & $96(80.0)$ & $256(76.88)$ \\
\cline { 2 - 5 } & Female & $53(24.88)$ & $24(20.0)$ & $77(23.12)$ \\
\hline
\end{tabular}

Between 2012 and 2015, the minimum and maximum rates of deaths, both at the scene of the accident and in the hospital, were observed in 2014 and 2015, respectively. The mortality rate was on a downward trend from 2012 to 2014, but unfortunately, a high increase in mortality rate was observed in 2015 compared to 2014. The highest rate of mortality at the scene of the accident and in the hospital was related to the spring with, respectively, $28.70 \%$ and $27.50 \%$ frequencies. The second highest rate of deaths was related to autumn. The injured were more likely to die between the hours of 18-24 than other hours (Table 2). 
Table 2: Frequency of death from road accidents, at different times from 2012 to 2015

\begin{tabular}{|c|c|c|c|c|}
\hline \multirow{2}{*}{\multicolumn{2}{|c|}{ Variable }} & \multicolumn{3}{|c|}{ Percentage, frequency, and number of deaths of individuals injured } \\
\hline & & Scene of the accident & Hospital & Generally \\
\hline \multirow{4}{*}{$\begin{array}{l}\text { Time of day } \\
\text { (hours) }\end{array}$} & 6-12 & $47(21.36)$ & $27(22.50)$ & $74(21 / 76)$ \\
\hline & 13-18 & $73(33.18)$ & $38(31.67)$ & $111(32.65)$ \\
\hline & 19-24 & $73(33.18)$ & $45(37.50)$ & $118(34.71)$ \\
\hline & 1-6 & $27(12.27)$ & $10(8 / 33)$ & $37(10 / 88)$ \\
\hline \multirow{4}{*}{ Season } & Spring & $64(28.70)$ & $33(27.50)$ & $97(28.28)$ \\
\hline & Summer & $50(22.42)$ & $27(22.50)$ & $77(22.45)$ \\
\hline & Autumn & $59(26.46)$ & $29(24.17)$ & $88(25.66)$ \\
\hline & Winter & $50(22.42)$ & $31(25.83)$ & $81(23.62)$ \\
\hline \multirow{4}{*}{ Year } & 2012 & $57(25.45)$ & $29(24.17)$ & $86(25.0)$ \\
\hline & 2013 & $54(24.11)$ & $29(24.17)$ & $83(24.13)$ \\
\hline & 2014 & $43(19.20)$ & $19(15.83)$ & $62(18.02)$ \\
\hline & 2015 & $70(31.25)$ & $43(35.83)$ & $113(32.85)$ \\
\hline
\end{tabular}

Most deaths at the scene of the accident and in the hospital occurred among vehicle drivers and occupants, respectively. In addition, 69\% of the deaths at the scene of the accident and
$64 \%$ of the deaths in the hospital occurred on the main road, and automobiles were more deadly than other vehicles. The second most deadly vehicle was the motorcycle (Table 3 ).

Table 3: Frequency of death, based on the condition of the injured, traffic passage, and vehicle from 2012 to 2015

\begin{tabular}{|c|c|c|c|c|}
\hline & \multirow{2}{*}{ Variable } & \multicolumn{3}{|c|}{ Percentage, frequency, and number of deaths of individuals injured } \\
\hline & & Scene of the accident & Hospital & Generally \\
\hline \multirow{4}{*}{$\begin{array}{c}\text { Traffic } \\
\text { passages }\end{array}$} & Highway & $23(12.04)$ & $13(11.21)$ & $36(11.73)$ \\
\hline & Main road & 132(69.11) & $75(64.66)$ & 207(67.43) \\
\hline & By-way & $25(13.09)$ & $17(14.66)$ & $42(13.68)$ \\
\hline & Rural road & $11(5.76)$ & $11(9.48)$ & $22(7.17)$ \\
\hline \multirow{4}{*}{$\begin{array}{c}\text { Role of } \\
\text { the } \\
\text { injured }\end{array}$} & Pedestrian & $18(10.47)$ & $22(21.36)$ & $40(14.55)$ \\
\hline & Driver & 73(42.44) & $50(48.54)$ & $123(44.73)$ \\
\hline & Occupant & 73(42.44) & $30(29.13)$ & $103(37.45)$ \\
\hline & Unknown & $8(4.65)$ & $1(0.97)$ & $9(3.27)$ \\
\hline \multirow{4}{*}{ Vehicle } & Automobile & $116(73.42)$ & $63(61.76)$ & $179(68.85)$ \\
\hline & Heavy vehicle & $9(5.7)$ & $5(4.9)$ & $14(5.38)$ \\
\hline & Motorcycle & $33(20.89)$ & $33(32.35)$ & $66(25.38)$ \\
\hline & Bike & $0(0.0)$ & $1(0.98)$ & $1(0.38)$ \\
\hline
\end{tabular}

The trauma to the head caused the highest rate of deaths of the injured at the scene of the accident and trauma to the head and organs caused the highest rate of deaths in the hospital. In general, death among the injured with head trauma, head and limbs, and multiple traumas accounted for $88.14 \%$ of deaths (Table 4). 
Table 4: Frequency of death, based on various types of trauma from 2012 to 2013

\begin{tabular}{|c|c|c|c|c|}
\hline \multirow{2}{*}{\multicolumn{2}{|c|}{ Variable }} & \multicolumn{3}{|c|}{ Percentage, frequency, and number of deaths of individuals injured } \\
\hline & & Scene of the accident & Hospital & Generally \\
\hline \multirow{10}{*}{$\begin{array}{l}\text { Types of } \\
\text { trauma }\end{array}$} & Head & $59(46.46)$ & $37(33.94)$ & $96(40.68)$ \\
\hline & Chest & $2(1.57)$ & $0(0.0)$ & $2(0.85)$ \\
\hline & Abdomen & $0(0.0)$ & $2(1.83)$ & $2(0.85)$ \\
\hline & Lower extremity & $2(1.57)$ & $3(2.75)$ & $5(2.12)$ \\
\hline & Spine & $3(2.36)$ & $4(3.67)$ & $7(2.97)$ \\
\hline & Head and limbs & $17(13.39)$ & $38(34.86)$ & $55(23.31)$ \\
\hline & Spine and limbs & $1(0.79)$ & $2(1.83)$ & $3(1.27)$ \\
\hline & Head and spine & $2(1.57)$ & $3(2.75)$ & $5(2.12)$ \\
\hline & Upper extremity & $0(0.0)$ & $4(3.67)$ & $4(1.69)$ \\
\hline & Multiple trauma & $41(32.29)$ & $16(14.67)$ & $57(24.0)$ \\
\hline
\end{tabular}

\section{Discussion}

The present study showed that most of the deceased were men, which is similar to findings of studies in Fars, Zanjan, Kermanshah, and Sistan, Iran (21-24). Men in Iran, especially in low-income families, have a greater role in the household economy (24, 25). The highest frequency of accidents occurred in the age group of 19-30 years, which is consistent with the study in Fars (21). Time has a great impact on causation and death due to incidents (7). Most deaths in road accidents occurred early in the night, which was in agreement with the results of the study in Fars (21), but was not in accordance with that of the study conducted on the basis of Iranian police data (7). The results of the present study are consistent with the peak of the traffic at sunset and the increase in road accidents (21). On the other hand, the darkness of night reduces the speed and suitable function of the 115 Emergency staff. At night, emergency personnel may not be able to take the necessary measures for the injured. Most road accidents leading to death had occurred in the spring and autumn, which was consistent with the studies in Sistan and Baluchestan, Kermanshah, and Khuzestan, Iran (22, 26, 27). However, this finding was not in agreement with that of the study in Zanjan and on the Iranian police data, which reported that the highest rate of deaths due to traffic accidents occurred in the summer and winter, respectively $(7,23)$. The lowest rate of deaths due to traffic accidents was related to the summer, which was not consistent with the results obtained in Sistan, Fars, Zanjan, Khuzestan, and Kermanshah, Iran, and from the Iranian police data $(7,21-23,27,28)$. There may be less traffic on the roads of this region due to the hot weather in the summer. The higher rate of road accidents in the spring and autumn necessitates the greater focus of the police (26) and the EMS in these two seasons. Perhaps it is possible to reduce the mortality rate among the injured by stationing the police and the 115 Emergency units in hazardous and crowded locations in high-risk seasons.

The injured were more likely to die with a traumatic head injury, which was consistent with the results of studies in Fars, Sistan and Baluchestan, Kermanshah, and Fars, Iran (21, 22, 24, 29). Head trauma occurred among drivers more than vehicle occupants (24). The reason may be the less usage of belts and helmets among drivers of this area. In general, the use of helmets among motorcycle riders $(30,31)$ and seat belts among drivers and vehicle occupants is very low (31) in Iran. Therefore, more attention should be paid by the authorities to the use of protective devices and educational and control programs to use safety devices should be prioritized.

Nearly $50 \%$ of the dead were drivers of vehicles, contrary to the results of studies in 
Babol and Kermanshah, Iran $(24,31)$. This confirms risky driving and lower rate of use of protective equipment among drivers in the area. After drivers, the largest number of deaths was related to occupants and pedestrians, respectively, which was similar to the results of the study in Kerman, Fars, and Khuzestan $(18,25,27)$. According to the results of the studies carried out in Sistan, the vehicles most commonly involved in traffic accidents were automobiles (22, 28), and heavy vehicles were less frequently involved in accidents.

Due to the high temperature, the people of this area use an automobile, especially on suburban roads. Driving an automobile without a suitable braking system and airbags due to the low financial strength of most people in this area can justify the high mortality rate among road accident victims in this area. The highest rate of deaths due to accidents occurred on main roads, which was consistent with the results of studies in Sistan and Khuzestan (22, 27). The lowest rate of accidents occurred on rural roads which was consistent with the findings of the study in Khuzestan (27). In this study, the researchers did not have access to the statistics of deaths among the injured during transference to the hospital due to the lack of completion of the mission form by 115 Emergency personnel and the lack of records for these deaths in the hospital. The other limitation of this study was the use of the 115 Emergency recorded data. These limitations may have affected the number of data in this study, especially the number of deaths during the transference to the hospital. Based on the results of this study, it is suggested that the national code be used in the 115 Emergency forms to reduce the number of lost data and provide the possibility of tracking information through the hospital and forensic medicine systems.

\section{Conclusion}

In this study, a higher rate of mortality was observed among drivers of motor vehicles than other groups. Most of the deaths were due to road accidents in the spring and autumn, and head trauma was more likely to result in death. It seems that through educating the public and raising public awareness regarding the use of helmets and seat belts, and stationing police and 115 Emergency units on main roads in the spring and autumn, it is possible to reduce the rate of deaths among road accident victims in this region in an effective way.

\section{Acknowledgment}

This article was extracted from a master's thesis. The authors wish to thank Dr. Amir Mahmoudi, the physician in chief of Imam Khomeini Hospital in Jiroft City, and those responsible for statistics and the archives of the hospital admission, and the 115 Emergency personnel.

Conflict of interests: None declared.

\section{References}

1. World Health Organization. Violence and Injury Prevention. Global status report on road safety 2015. Geneve: World Health Organization; 2015. Available from: http://www.who.int/violence_injury_preventio n/road_safety_status/2015/en/

2. World Health Organization. Media centre, Fast sheets, Road traffic injuries. Geneve: World Health Organization; 2017. Available from: http://www.who.int/mediacentre/factsheets/fs3 58/en/

3. Yavari P. Epidemiology textbook of prevalent diseases in iran. $1^{\text {st }}$ ed. Rasht: Gap; 2014. P.159-68.

4. World Health Organization. World Health Statistics 2017: Monitoring Health for the SDGs Sustainable Development Goals. Geneve: World Health Organization; 2017. Available from: http://apps.who.int/iris/bitstream/10665/25533 6/1/9789241565486-eng.pdf

5. World Health Organization. Global Health Observatory (GHO) data, World health statistics 2017: Monitoring health for the SDGs. Geneve: World Health Organization; 2017. Available from: http://www.who.int/gho/publications/world_he alth_statistics/2017/en/ 
6. World Health Organization. Global Health Observatory (GHO) data, Iran (Islamic Republic of): country profiles. Geneve: World Health Organization; 2017. Available from: http://www.who.int/gho/countries/irn/country_ profiles/en/

7. Mehmandar M, Soori H, Amiri M, Norouzirad R, Khabzkhoob M. Risk factors for fatal and nonfatal road crashes in iran. Iran Red Crescent Med J 2014; 16(8):e10016.

8. Azami-Aghdash S, Gorji HA, SadeghiBazargani H, Shabaninejad H. Epidemiology of road traffic injuries in Iran: based on the data from Disaster Management Information System (DMIS) of the Iranian Red Crescent. Iran Red Crescent Med J 2017; 19(1):e38743.

9. Wilson $\mathrm{MH}$, Habig $\mathrm{K}$, Wright $\mathrm{Ch}$, Hughes A, Davies G, Imray ChHE. Pre-hospital emergency medicine. The Lancet. 2015; 386(10012):2526-34.

10. Adib-Hajbaghery M, Maghaminejad F. Epidemiology of patients with multiple trauma and the quality of their prehospital respiration management in Kashan, Iran: six months assessment. Arch Trauma Res 2014; 3(2):e17150.

11. Gomes E, Araújo R, Carneiro A, Dias C, Costa-Pereira A, Lecky FE. The importance of pre-trauma centre treatment of life-threatening events on the mortality of patients transferred with severe trauma. Resuscitation 2010; 81(4):440-5.

12. World Health Organization. Violence and Injury Prevention. World report on road traffic injury prevention. Geneve: World Health Organization; 2004. Available from: http://www.who.int/violence_injury_preventio n/publications/road_traffic/world_report/en/

13. Peden M. Global collaboration on road traffic injury prevention. Int J Inj Contr Saf Promot 2005; 12(2):85-91.

14. Khorasani-Zavareh D, Khankeh HR, Mohammadi R, Laflamme L, Bikmoradi A, Haglund BJ. Post-crash management of road traffic injury victims in Iran. Stakeholders' views on current barriers and potential facilitators. BMC Emerg Med 2009; 9:8.

15. United Nations Children's Fund. Media centre, Road traffic injuries in Iran and their prevention, a worrying picture. Islamic Republic of Iran: United Nations Children's Fund (UNICEF); 2014. Available from: https://www.unicef.org/iran/media_4783.html

16. Bigdeli M, Khorasani-Zavareh D, Mohammadi R. Pre-hospital care time intervals among victims of road traffic injuries in Iran. A crosssectional study. BMC Public Health 2010; 10:406.
17. Alinia S, Khankeh H, Maddah SS, Negarandeh R. Barriers of pre-hospital services in road traffic injuries in Tehran: the viewpoint of service providers. Int J Community Based Nurs Midwifery 2015; 3(4):272-82.

18. Khorrami Z, Hashemi Nazari SS, Ghadirzadeh MR. An epidemiology study of deaths from road traffic accidents. Journal of Safety Promotion and Injury Prevention 2016; 4(4):217-24.

19. Statistical Center of Iran (SCI). Results of the 2016 National Population and Housing Census [Internet]. 2016 [cited 12 November 2017]; Available from: https://www.amar.org.ir/english/Statistics-byTopic/Population\#2224493-releases

20. Iranian Legal Medicine Organization. General Office of Legal Medicine, Kerman Province. Statistics deaths and injuries caused by traffic accidents referral to forensic medicine in Kerman province during 2016-2017. Kerman: General Office of Legal Medicine; 2016 March 20 - 2017 March 20.

21. Hasanzadeh J, Moradinazar M, Najafi F, Ahmadi-Jouybary T. Trends of mortality of road traffic accidents in Fars Province, Southern Iran, 2004-2010. Iran J Public Health 2014; 43(9):1259-65.

22. Taravatmanesh S, Hashemi-Nazari SS , Ghadirzadeh MR, Taravatmanesh L. Epidemiology of fatal traffic injuries in the Sistan and Baluchistan province in 2011. Journal of Safety Promotion and Injury Prevention 2015; 3(3):161-8.

23. Yousefzadeh-Chabok S, Ranjbar-Taklimie F, Malekpouri R, Razzaghi A. A time series model for assessing the trend and forecasting the road traffic accident mortality. Arch Trauma Res 2016; 5(3):e36570.

24. Hamzeh B, Najafi F, Karamimatin B, Ahmadijouybari T, Salari A, Moradinazar M. Epidemiology of traffic crash mortality in west of Iran in a 9 year period. Chin J Traumatol 2016; 19(2):70-4.

25. Ghadipasha M, Vaghefi SS, Kazemi Esfeh S, Teimoori M, Ouhadi AR, Mirhosseini SM. An annual analysis of clinical diagnosis versus autopsy findings in fatal motor vehicle accident in legal medicine organization of Kerman province, Iran. J Forensic Leg Med 2015; 34:164-7.

26. Zolala F, Haghdoost AA, Ahmadijouybari T, Salari A, Bahrampour A, Baneshi MR, et al. Forecasting the trend of traffic accident mortality in west Iran. Health Scope 2016;5(3):e31336.

27. Rajaei Behbahani N, Mohammadi MJ, Hashemi Nazari SS, Ghadirzadeh M, 
Hassanipour S. Studying the epidemiology of fatal traffic accidents in the Khuzestan Province. Jundishapur Journal of Health Sciences 2016; 8(2):e32114.

28. Izadi N, Najafi Farid F, Khosravi A, Hashemi Nazari SS, Salari A, Soori H. Estimation of mortality and calculated years of lost life from road traffic injuries. Journal of Mazandaran University of Medical Sciences 2014; 24(112): 51-8.

29. Heydari ST, Maharlouei NN, Foroutan A, Sarikhani Y, Ghaffarpasand F, Hedjazi A, et al. Fatal motorcycle accidents in Fars Province,
Iran: a community-based survey. Chin $\mathrm{J}$ Traumatol 2012; 15(4):222-7.

30. Sadeghi Bazargani H, Saadati M, Rezapour R, Abedi L. Determinants and barriers of helmet use in Iranian motorcyclists: a systematic review. J Inj Violence Res 2017; 9(1):61-7.

31. Modarres SR, Shokrollahi MH, Yaserian M, Rahimi M, Amani N, Manouchehri A. Epidemiological characteristics of fatal traumatic accidents in Babol, Iran: a hospitalbased survey. Bull Emerg Trauma 2014; 2(4):146-50 